\title{
EFFECT: a randomized phase II study of efficacy and impact on function of two doses of nab-paclitaxel as first-line treatment in older women with advanced breast cancer
}

Laura Biganzoli ${ }^{1 *}$ (D, Saverio Cinieri², Rossana Berardi ${ }^{3}$, Rebecca Pedersini ${ }^{4}$, Amelia McCartney ${ }^{1}$, Alessandro Marco Minisini ${ }^{5}$, Elena Rota Caremoli, Simon Spazzapan ${ }^{7}$, Emanuela Magnolfi $i^{8}$, Antonella Brunello ${ }^{9}$, Emanuela Risi ${ }^{1}$, Raffaella Palumbo ${ }^{10}$, Silvana Leo ${ }^{11}$, Marco Colleoni ${ }^{12}$, Sara Donati ${ }^{13}$, Sabino De Placido ${ }^{14}$, Laura Orlando ${ }^{2}$, Mirco Pistelli ${ }^{3}$, Veronica Parolin ${ }^{15}$, Anna Mislang ${ }^{1,16}$, Dimitri Becheri ${ }^{17}$, Fabio Puglisi ${ }^{5,7}$, Giuseppina Sanna ${ }^{1}$, Elena Zafarana ${ }^{1}$, Luca Boni ${ }^{18}$ and Giuseppe Mottino ${ }^{17}$

\begin{abstract}
Background: Limited data are available regarding the use of nab-paclitaxel in older patients with breast cancer. A weekly schedule is recommended, but there is a paucity of evidence regarding the optimal dose. We evaluated the efficacy of two different doses of weekly nab-paclitaxel, with a specific focus on their corresponding impact on patient function, in order to address the lack of data specifically relating to the older population.

Methods: EFFECT is an open-label, phase II trial wherein 160 women with advanced breast cancer aged $\geq 65$ years were enrolled from 15 institutions within Italy. Patients were randomly assigned 1:1 to receive nab-paclitaxel $100 \mathrm{mg} /$ $\mathrm{m}^{2}$ (arm A) or $125 \mathrm{mg} / \mathrm{m}^{2}$ (arm B) on days 1, 8, and 15 on a 28-day cycle, as first-line treatment for advanced disease. The primary endpoint was event-free survival (EFS), wherein an event was defined as disease progression (PD), functional decline (FD), or death. In each arm, the null hypothesis that the median EFS would be $\leq 7$ months was tested against a one-sided alternative according to the Brookmeyer Crowley test. Secondary endpoints included objective response rate (ORR), clinical benefit rate (CBR), progression-free survival (PFS), overall survival (OS), and safety.

(Continued on next page)
\end{abstract}

\footnotetext{
* Correspondence: laura.biganzoli@uslcentro.toscana.it

1"Sandro Pitigliani" Department of Medical Oncology, Hospital of Prato, ASL Toscana Centro, Prato, Italy

Full list of author information is available at the end of the article
}

(c) The Author(s). 2020 Open Access This article is licensed under a Creative Commons Attribution 4.0 International License, which permits use, sharing, adaptation, distribution and reproduction in any medium or format, as long as you give appropriate credit to the original author(s) and the source, provide a link to the Creative Commons licence, and indicate if changes were made. The images or other third party material in this article are included in the article's Creative Commons licence, unless indicated otherwise in a credit line to the material. If material is not included in the article's Creative Commons licence and your intended use is not permitted by statutory regulation or exceeds the permitted use, you will need to obtain permission directly from the copyright holder. To view a copy of this licence, visit http://creativecommons.org/licenses/by/4.0/ The Creative Commons Public Domain Dedication waiver (http://creativecommons.org/publicdomain/zero/1.0/) applies to the data made available in this article, unless otherwise stated in a credit line to the data. 
(Continued from previous page)

Results: After a median follow-up of 32.6 months, 140 events were observed in 158 evaluable patients. Median EFS was 8.2 months $(90 \% \mathrm{Cl}, 5.9-8.9 ; p=0.188)$ in arm A vs 8.3 months (90\% Cl, 6.2-9.7, $p=0.078)$ in arm B. Progression-free survival, overall survival, and response rates were similar in both groups. A higher percentage of dose reductions and discontinuations due to adverse events (AEs) was noted in arm B. The most frequently reported non-haematological AEs were fatigue (grade [G] 2-3 toxicity occurrence in arm A vs B, 43\% and 51\%, respectively) and peripheral neuropathy (G2-3 arm A vs B, 19\% and 38\%, respectively).

Conclusion: Pre-specified outcomes were similar in both treatment arms. However, $100 \mathrm{mg} / \mathrm{m}^{2}$ was significantly better tolerated with fewer neurotoxicity-related events, representing a more feasible dose to be recommended for older patients with advanced disease.

Trial registration: EudraCT, 2012-002707-18. Registered on June 4, 2012. NIH ClinicalTrials.gov, NCT02783222. Retrospectively registered on May 26, 2016.

Keywords: Nab-paclitaxel, Functional decline, Toxicity, Breast cancer, Older adults, Metastatic

\section{Background}

Older patients are at higher risk of chemotherapyrelated toxicities in comparison with younger adults [1]. Weekly solvent-based taxanes, such as paclitaxel and docetaxel, are amongst the recommended agents to treat older patients with advanced breast cancer $(A B C)$ [2]. However, close monitoring is required given that treatment-induced side effects, particularly neurotoxicity and fatigue, place older patients at risk of subsequent functional decline (FD) [3-7]. Nanoparticle albuminbound paclitaxel (nab-paclitaxel) does not require steroid premedication and is associated with a lower rate of hypersensitivity reactions [8-10], thus representing an efficacious and safe alternative to solvent-based taxanes. Additionally, recovery from nab-paclitaxel-induced neurotoxicity is reputedly shorter than with solventbased taxanes [8,9], which may subsequently produce a reduction in negative functional impact. Limited data exist regarding the use of nab-paclitaxel in elderly patients, and uncertainty still prevails regarding the ideal dose to be used in this population. A previous post hoc analysis of two studies investigated the safety and efficacy of q1w and q3w nab-paclitaxel compared with q3w solvent-based paclitaxel and docetaxel in older patients with ABC [11]. Two doses of weekly nab-paclitaxel (150 $\mathrm{mg} / \mathrm{m}^{2}$ and $100 \mathrm{mg} / \mathrm{m}^{2}$, on days 1,8 , and 15 on a 28 day cycle) were evaluated. Nab-paclitaxel was found to be safer and more efficacious when administered weekly. However, these conclusions were limited by way of a small studied group: only 24 patients aged $\geq 65$ years were treated with weekly nab-paclitaxel. Additionally, the reported 20\% incidence of grade 3 sensory neuropathy was concerning.

The EFFECT trial aimed to identify the optimal weekly dose of nab-paclitaxel that could be effectively used in older patients with $A B C$, whilst also integrating geriatric assessment tools to evaluate the impact of treatment on function.

\section{Methods}

\section{Study design and conduct}

EFFECT (EudraCT 2012-002707, ClinicalTrials.gov identifier: NCT02783222) is an open-label, randomized, phase II study evaluating two doses of weekly nabpaclitaxel as the first-line treatment in older women with ABC. Patients were recruited across 15 cancer centres in Italy, with prospective approval of the protocol by local independent ethics committees at each site. Written informed consent was obtained from all patients.

\section{Patients and treatments}

Eligible patients were female aged $\geq 65$ years with pathologically confirmed $A B C$ of any hormone receptor (HR) and HER2 status, and a history of no prior lines of treatment in the advanced setting. In line with the absence of inclusion of anti-HER2 agents in the trial protocol, women with HER2-positive disease were required to have contraindications to their administration. Additional inclusion criteria were Eastern Cooperative Oncology Group (ECOG) performance status $0-2$, the presence of measurable or evaluable disease according to the Response Evaluation Criteria in Solid Tumors version 1.1 (RECIST v1.1), adequate organ function, and an absence of active/symptomatic central nervous system metastases and/or grade $\leq 1$ peripheral neuropathy.

Using an interactive web response system (IWRS) and the minimization algorithm, patients were centrally randomized 1:1 to receive nab-paclitaxel $100 \mathrm{mg} / \mathrm{m}^{2}$ (arm A) or $125 \mathrm{mg} / \mathrm{m}^{2}$ (arm B) on days 1,8 , and 15 on a 28day cycle. Patients were stratified according to age (6574 vs $\geq 75$ years), concomitant diabetes (yes/no), instrumental activity of daily living (IADL) impairment (yes/ no), presence of any grade 3-4 illness according to the Cumulative Illness Rating Scale-Geriatric (CIRS-G) score (yes/no), measurable vs evaluable disease, treating centre, and prior exposure to taxanes (yes/no). 
Dose modifications for specific treatment-emergent toxicities were mandated by the protocol. Patients continued on trial-assigned treatment until the point of FD, unacceptable toxicity, consent withdrawal, disease progression (PD), or death, or at the discretion of the treating physician.

\section{Study endpoints}

The primary study endpoint was event-free survival (EFS), wherein an "event" was either FD, PD, or death. FD was defined as a decrease of at least one point from baseline values of activity of daily living (ADL) and/or instrumental activity of daily living (IADL) considered by the investigator to be treatment-related and confirmed at subsequent cycle. Secondary endpoints included objective response rate (ORR), clinical benefit rate (CBR), PFS, overall survival (OS), and safety. ORR was defined by the percentage sum of complete responses (CR) and partial responses (PR). CBR was calculated by combining $C R, P R$, and stable disease (SD). ORRs and CBRs were determined only in patients with measurable disease. The calculation of all time-to-event intervals started from the date of randomization. All serious and non-serious adverse events (AEs) were graded according to the Common Terminology Criteria for Adverse Events (CTCAE) version 4.03. Both events related and unrelated to the study treatment were captured.

\section{Assessments}

Tumours were evaluated according to RECIST v1.1 within 28 days before randomization and then every 12 weeks until PD. The presence of comorbidities and functional impairments was assessed at baseline using CIRSG [12], ADL [13], and IADL [14] instruments. ADLs and IADLs were also re-evaluated on day 1 of each cycle. AEs were recorded and graded according to CTCAE version 4.03 and were evaluated by the investigator at every patient visit from baseline until up to 30 days after discontinuation of trial treatment.

\section{Statistical analysis}

Efficacy analyses were performed on the modified intention-to-treat population, which included all randomly assigned patients who received at least one dose of the study drug. In each arm, the null hypothesis that the median EFS would be $\leq 7$ months was tested against a one-sided alternative according to the Brookmeyer Crowley test [15]. It was estimated that with the enrolment of 144 patients (72 in each arm), every hypothesis test would have a type I error rate of $5 \%$ and a power of $90 \%$ when the true median EFS was $\geq 12$ months. The distributions of all studied patients according to demographic, clinical, and biologic characteristics and categorical outcomes were summarized as frequencies and percentage. Continuous variables were reported as median and range of variation. The median period of follow-up and its interquartile range were calculated for the entire study cohort according to the reverse KaplanMeier method. Distributions of EFS, PFS, and OS were estimated using the Kaplan-Meier product-limit method. According to the study design, no formal statistical comparisons between the results observed in the two treatment arms were planned or performed. The SAS software version 9.2 (SAS Institute, Cary, NC) was used for the statistical analysis.

During data cleaning, it was observed that some patients had two consecutive reports of G2/3 neurotoxicity or fatigue (which, by CTCAE definition, imply functional impairment of ADLs or IADLs) who were not also reported as having FD. Accordingly, a central review was undertaken. For reports of neurotoxicity, FD was confirmed and recorded in the setting of two consecutive reports of grade 2 or 3 episodes. In the setting of two consecutive reports of grade 2 or 3 fatigue, the responsible investigator was contacted, and FD was declared/ confirmed only when fatigue was deemed to be treatment-related. The primary study endpoint is subsequently reported both by the investigator and by a central review.

As there is an ongoing and unresolved discussion regarding which age should be used to define "elderly" patients, an unplanned subgroup analysis was also conducted to evaluate major treatment outcomes in patients aged $\geq 75$ years.

\section{Results}

Between January 2013 and September 2016, 160 patients were accrued and randomized in a 1:1 fashion. Overall, 79 patients per arm were evaluable for efficacy and safety analyses (see CONSORT diagram: Fig. 1). The baseline demographics are summarized in Table 1. The median age was 72 years in arm A and 73 years in arm B. Overall, approximately $70 \%$ were aged $\geq 70$ years and $>40 \%$ were $\geq 75$ years. The majority of patients had excellent baseline functional status and well-controlled comorbidities.

\section{Treatment exposure}

Overall in both arms, patients received a median of 6 cycles of nab-paclitaxel. In patients aged 75 and over, those in arm A completed a median of 6 cycles, with a median of 5 cycles completed by those assigned to arm B (Table 2). Dose delays were reported in $21 \%$ of cycles undertaken in arm A and in 23\% of cycles in arm B. More than $70 \%$ of patients had dose reductions overallhowever, a higher percentage of dose reductions per cycle was noted in arm B (39\% vs 58\%) (Table 2). The main reasons for treatment discontinuations were (arm 


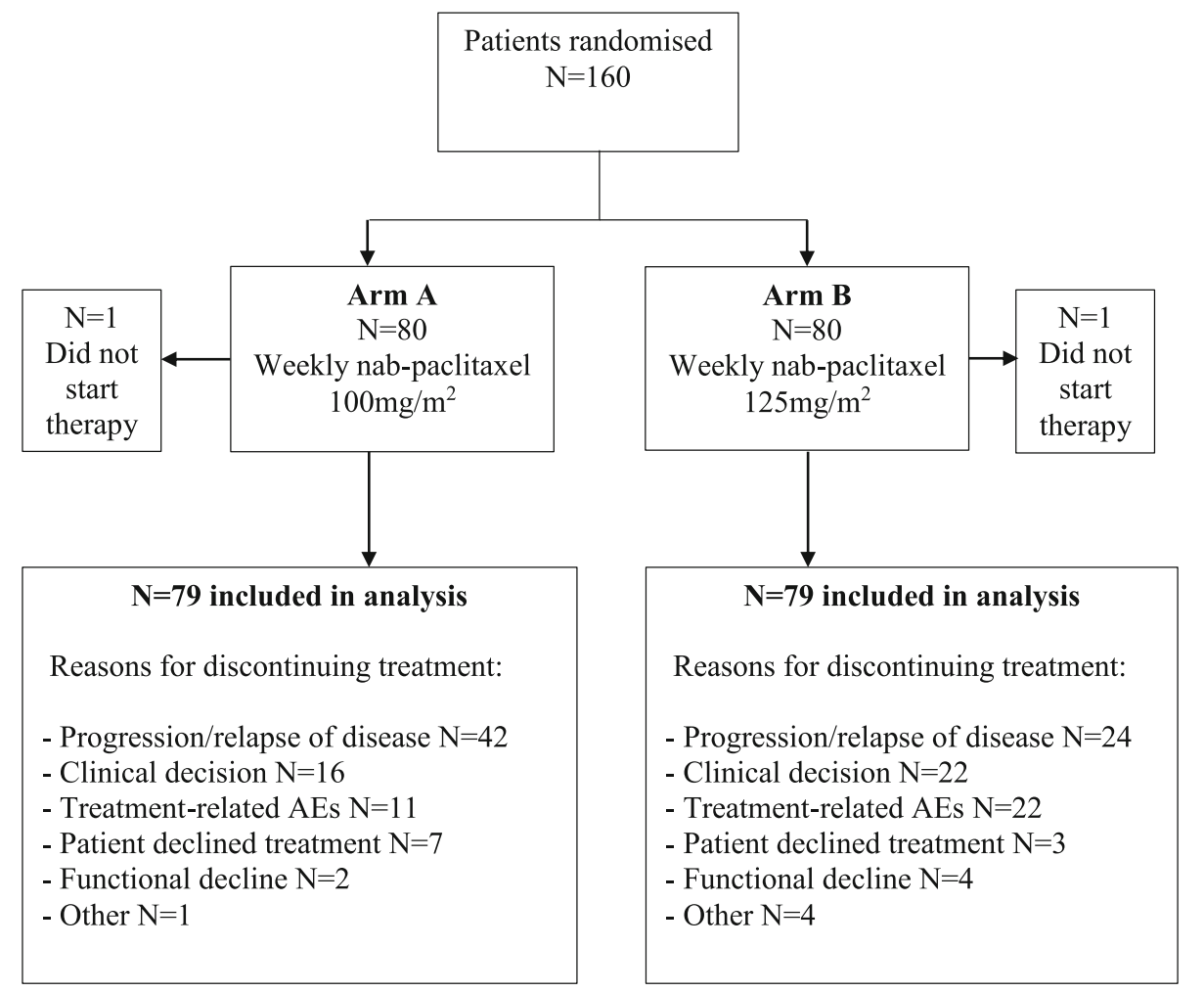

Fig. 1 CONSORT diagram illustrating the disposition to treatment arms, plus reasons for discontinuing treatment on trial

A vs B) PD (53\% vs $30 \%)$, clinical decision (20\% vs $28 \%$ ), AEs ( $14 \%$ vs $28 \%$ ), patient choice ( $9 \%$ vs $4 \%$ ), and FD (2.5\% vs $5 \%)$.

\section{Efficacy}

At a median follow-up of 32.6 months (interquartile range, 23.6-41.6), 140 events were observed. The majority of reported events-over $75 \%$ in each arm-consisted of PD, with on average only $7 \%$ of patients overall experiencing FD (Table 3). The median EFS was 8.2 (90\% confidence interval (CI) 5.9-8.9; Brookmeyer-Crowley like test $p=0.188)$ and $8.3 \quad(90 \% \quad$ CI $\quad 6.2-9.7$; Brookmeyer-Crowley like test $p=0.078$ ) months for arms $\mathrm{A}$ and $\mathrm{B}$, respectively (Fig. 2a). At the central review, FD was identified in $17 \%$ of patients on average (Table 3), with a consequent comparative reduction in the median EFS by 2 months in both arms (median EFS 6.2 months vs 6.4 months for arms $\mathrm{A}$ and $\mathrm{B}$, respectively) (Fig. 2b). Efficacy outcomes are reported in Table 4.

In patients with measurable disease at baseline $(n=$ 125), the ORR was $40 \%$ in arm $A$ and $42 \%$ in arm B, with a CBR of $80 \%$ and $69 \%$, respectively. In those patients who discontinued nab-paclitaxel in the absence of PD, $27 \%(n=21)$ in arm A and $34 \%(n=27)$ in arm B received a subsequent line of therapy. The median OS in arm A was 22.4 months (95\% CI 17.0-35.6) and 20.7 months (95\% CI 16.8-28.6) in arm B. The main cause of death in both arms was PD (arm A, $n=48$ [61\%]; arm B, $n=45[57 \%])$.

No difference in the distribution of events was observed within the subgroup of patients aged $\geq 75$ years (Table 3). In this group, the median EFS was 8.3 months (90\% CI 5.7-8.9) in arm A and 8.2 months (90\% CI 3.510.9) in arm B. Similar outcomes were observed when EFS was evaluated according to age subgroup (data not shown). The median PFS was 8.3 months (95\% CI 5.910.5) for arm A and 8.8 months (95\% CI 7.4-10.3) for arm B.

\section{Safety}

AEs are reported in Table 5 and are consistent with the known safety profile of nab-paclitaxel in the general population. Myelotoxicity was moderate: one patient in arm A (1\%) and three (4\%) in arm B experienced G4 neutropenia. G3 febrile neutropaenia was reported in one (1\%) and two patients $(2.5 \%)$ in arms $\mathrm{A}$ and $\mathrm{B}$, respectively. The most frequently reported nonhaematological AEs were fatigue and peripheral neuropathy. In arm B, G2/3 neurotoxicity occurred more frequently (38\% vs $19 \%$ in arm A) and with a shorter median time to onset than arm A. In arm A, G2 neurotoxicity was reported after a median of 6.5 cycles (range, 2-11), with G3 reported after a median of 6 cycles (range, 3-9). In contrast, G2 neurotoxicity was reported 
Table 1 Baseline characteristics of the ITT population, by treatment arm and age. Reported as $n$ (\%) unless otherwise indicated

\begin{tabular}{|c|c|c|c|c|}
\hline \multirow[t]{2}{*}{ Characteristics } & \multicolumn{2}{|c|}{ Arm A, $100 \mathrm{mg} / \mathrm{m}^{2}$} & \multicolumn{2}{|l|}{ Arm B, 125 mg/m² } \\
\hline & Overall $(\boldsymbol{N}=79)$ & Patients aged $75+(\boldsymbol{N}=33)$ & Overall $(\boldsymbol{N}=79)$ & Patients aged $75+(\boldsymbol{N}=33)$ \\
\hline Median age in years (range) & $72(65-84)$ & $80(75-84)$ & $73(65-88)$ & $77(75-88)$ \\
\hline \multicolumn{5}{|l|}{ Age } \\
\hline $65-69$ & $28(35)$ & - & $21(27)$ & - \\
\hline $75+$ & $33(42)$ & $33(100)$ & $33(42)$ & $33(100)$ \\
\hline \multicolumn{5}{|l|}{ ECOG PS } \\
\hline 0 & $51(65)$ & $20(61)$ & $43(54)$ & $19(58)$ \\
\hline 1 & $19(24)$ & $9(27)$ & $32(41)$ & $13(40)$ \\
\hline 2 & $9(11)$ & $4(12)$ & $4(5)$ & $1(3)$ \\
\hline \multicolumn{5}{|l|}{ ADL scores } \\
\hline Impaired [range] & $14(18)[5 / 6-4 / 6]$ & $6(18)[5 / 6-5 / 6]$ & $20(25)[5 / 6-1 / 6]$ & $8(24)[5 / 6-1 / 6]$ \\
\hline Missing data & $2(2)$ & $2(2)$ & 0 & 0 \\
\hline \multicolumn{5}{|l|}{ IADL scores } \\
\hline Impaired [range] & $20(25)[7 / 8-2 / 8]$ & 9 (3) $[7 / 8-4 / 8]$ & $20(25)[7 / 8-2 / 8]$ & $8(24)[7 / 8-3 / 8]$ \\
\hline Missing data & $2(2)$ & $1(3)$ & 0 & 0 \\
\hline \multicolumn{5}{|l|}{ Comorbidities } \\
\hline Any grades $3-4$ & $8(10)$ & $6(18)$ & $10(13)$ & $3(9)$ \\
\hline Diabetes mellitus & $9(11)$ & $6(18)$ & $11(14)$ & $4(12)$ \\
\hline \multicolumn{5}{|l|}{ HR status } \\
\hline $\mathrm{ER}-$ and $\mathrm{PgR}-$ & $9(11)$ & $5(15)$ & $8(10)$ & $4(12)$ \\
\hline ER+ and/or PgRt & $68(86)$ & $28(85)$ & $67(85)$ & $28(85)$ \\
\hline Missing data & $2(3)$ & 0 & $4(5)$ & $1(3)$ \\
\hline \multicolumn{5}{|l|}{ HER2 status } \\
\hline Positive & $2(3)$ & $1(3)$ & 0 & 0 \\
\hline Missing data & $5(6)$ & $2(6)$ & $10(13)$ & $4(12)$ \\
\hline Prior taxane use & $11(14)$ & $3(9)$ & $10(13)$ & $1(3)$ \\
\hline Measurable disease & $60(76)$ & $22(67)$ & $65(82)$ & $28(85)$ \\
\hline Visceral disease & $56(71)$ & $22(67)$ & $55(69)$ & $25(76)$ \\
\hline
\end{tabular}

$A D L$ activities of daily living, ECOG PS Eastern Cooperative Oncology Group Performance Status, IADL instrumental ADL, + positive, - negative

Table 2 Treatment exposure, described by randomized arm, as well as within the subgroup aged $\geq 75$. Reported as $n$ (\%) unless otherwise stated

\begin{tabular}{|c|c|c|c|c|}
\hline \multirow[t]{2}{*}{ Regimen received } & \multicolumn{2}{|c|}{ Arm A, 100 mg/m² } & \multicolumn{2}{|c|}{ Arm B, $125 \mathrm{mg} / \mathrm{m}^{2}$} \\
\hline & All $(\boldsymbol{N}=79)$ & Pts aged $75+(\boldsymbol{N}=33)$ & All $(\boldsymbol{N}=79)$ & Pts aged $75+(\boldsymbol{N}=33)$ \\
\hline Total $n$ of cycles & 594 & 214 & 443 & 180 \\
\hline Median $n$ cycles (range) & $6(1-28)$ & $6(1-19)$ & $6(1-22)$ & $5(1-11)$ \\
\hline \multicolumn{5}{|l|}{ Dose delays } \\
\hline$N$ of patients & $52(66)$ & $19(58)$ & $50(63)$ & $18(55)$ \\
\hline$N$ of cycles & $127(21)$ & $43(20)$ & $100(23)$ & $35(19)$ \\
\hline \multicolumn{5}{|l|}{ Dose reductions } \\
\hline$N$ of patients & $57(72)$ & $22(68)$ & $63(80)$ & $23(70)$ \\
\hline$N$ of cycles & 234 (39) & $78(36)$ & $257(58)$ & $101(56)$ \\
\hline
\end{tabular}


Table 3 Primary endpoint-related events in the overall population and in patients aged 75 years and older. Reported as $N$ (\%) unless otherwise indicated

\begin{tabular}{|c|c|c|c|c|}
\hline \multirow[t]{2}{*}{ Event } & \multicolumn{2}{|c|}{$\operatorname{Arm~A,~} 100 \mathrm{mg} / \mathrm{m}^{2}$} & \multicolumn{2}{|c|}{ Arm B, 125 mg/m² } \\
\hline & All $(N=79)$ & Pts aged $75+(N=33)$ & All $(N=79)$ & Pts aged $75+(N=33)$ \\
\hline \multicolumn{5}{|l|}{ Investigator reported } \\
\hline Pts with reported event & $69(87)$ & $31(94)$ & $71(90)$ & $29(88)$ \\
\hline PD & $61(77)$ & $28(85)$ & $60(76)$ & $23(70)$ \\
\hline FD & $4(5)$ & $1(3)$ & $7(9)$ & $5(13)$ \\
\hline Death & $4(5)$ & $2(6)$ & $4(5)$ & $1(3)$ \\
\hline \multicolumn{5}{|l|}{ Central review } \\
\hline Pts with reported event & $72(91)$ & $32(97)$ & $74(94)$ & $30(91)$ \\
\hline PD & $56(71)$ & $25(76)$ & $55(70)$ & $23(70)$ \\
\hline $\mathrm{FD}$ & $13(16)$ & $6(18)$ & $14(18)$ & $5(15)$ \\
\hline Death & $3(4)$ & $1(3)$ & $5(6)$ & $2(6)$ \\
\hline
\end{tabular}

FD functional decline, PD disease progression, Pts patients

in arm B after a median of 5 cycles (range, 1-11), with G3 reported after a median of 4.5 cycles (range, $3-8)$. Severe AEs were reported in ten patients (13\%) in each arm. Treatment-related toxicity was reported as the cause of death in three patients: one patient in arm A died due to acute renal failure secondary to diarrhoea; in arm B, one patient died from complications of severe diarrhoea and another from septic shock secondary to Clostridium difficile infection after a single dose of weekly nab-paclitaxel, on a background of long-term use of corticosteroids and proton pump inhibitors (PPI).

AEs in the patient subgroup aged $\geq 75$ years are reported in Additional File 1: Table S1. Of note, two out of the three grade 5 toxicities were registered in this age group. The incidence of grade $2-3$ fatigue and neurotoxicity was positively correlated to age in patients treated in $\operatorname{arm~B}$, but not observed in arm A (Additional File 2: Table S2).

\section{Discussion}

EFFECT was designed to prospectively identify a dose of nab-paclitaxel that might be safely and efficaciously administered weekly to older women with $\mathrm{ABC}$. Based on the two weekly doses previously evaluated by Gradishar et al. [9] and later explored in a post hoc analysis which concentrated specifically on the older population [11], $150 \mathrm{mg} / \mathrm{m}^{2}$ was not explored as it was considered too toxic for older patients. The studied doses of 100 and $125 \mathrm{mg} / \mathrm{m}^{2}$ were chosen based on previous results of a phase II study evaluating these two doses in patients with $A B C$ heavily pretreated with taxanes, which showed weekly nab-paclitaxel $100 \mathrm{mg} / \mathrm{m}^{2}(n=75)$ had similar antitumour activity and more favourable safety profile than $125 \mathrm{mg} / \mathrm{m}^{2} \quad(n=106)$ [16]. Due to the linear pharmacokinetics of nab-paclitaxel, we considered it worthy to investigate both doses in the first-line setting.
Our study showed that the administration of both doses of nab-paclitaxel was feasible, with a comparable median number of delivered cycles in the two arms, but a higher percentage of dose-reduced cycles, and higher rates of treatment discontinuation due to AEs observed in arm B. The two weekly doses of nab-paclitaxel were equally effective and were associated with a similar incidence of FD, noting that the rate of FD increased on the unplanned central review. However, the lower incidence of neurotoxicity observed in arm A makes $100 \mathrm{mg} / \mathrm{m}^{2}$ a more feasible dose in older patients with $\mathrm{ABC}$.

The incidence of neurotoxicity and fatigue are integral concerns related to the administration of taxanes. As maintenance of functional status is fundamental to effective care of the elderly, loss of function was included in the EFS evaluation in this study. As such, EFFECT specifically set an elderly-oriented primary endpoint, wherein EFS was calculated based on the occurrence of an event (PD, FD, or death). Central review of data revealed a higher rate of FD than what was initially reported by the investigators, highlighting that FD is commonly under-reported. The explanation for this may be attributed to a lack of familiarity in evaluating FD in clinical trials, as well as FD being a phenomenon that is perhaps under-appreciated in the clinical setting as a whole. It should be noted that due to the restrictive definition set for FD by the study, the increased observation of grade 2-3 fatigue and neurotoxicity reported in arm $\mathrm{B}$ did not translate into a higher incidence of FD between the two treatment arms.

As expected, fatigue and peripheral neuropathy were the most frequent non-haematological AEs in both arms. Notably, in arm B, the incidence of grade 2-3 neuropathy was double than that of arm A (19\% vs 38\%). Contrastingly, at $100 \mathrm{mg} / \mathrm{m}^{2}$, the incidence of grade 2 and 3 neurotoxicity was $15 \%$ and $4 \%$, respectively. These 


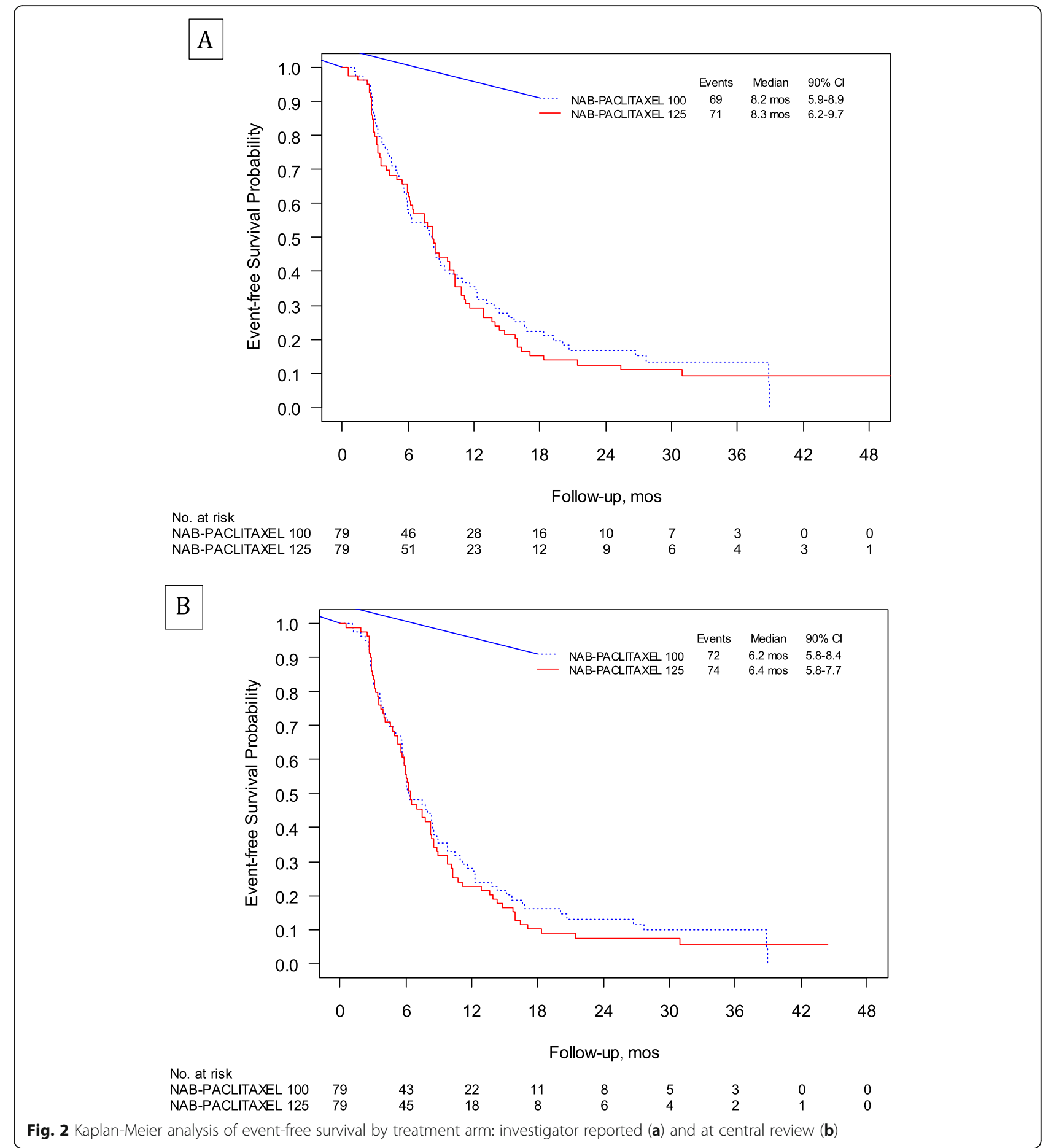

data are comparable with those reported by Gradishar et al. in an unselected population $[9,10]$, and equate favourably with those reported by Aapro et al. in patients aged $\geq 65$ years, treated at the same dose of weekly nab-paclitaxel (21\% grade 3, grade 2 not reported) [11].

In EFFECT, three deaths were reported as the result of AEs. Diarrhoea was associated with the cause of death in all three cases, wherein patients experienced secondary severe dehydration, end-stage renal failure, and septic shock. Chemotherapy-associated diarrhoea represents a significant event which requires close monitoring and aggressive management in older patients, who are at the highest risk of developing severe and fatal complications from associated dehydration, renal insufficiency, electrolyte imbalance, or infection [17, 18]. Age and recent antibiotic exposure are well-recognized risk factors for 
Table 4 Efficacy outcomes, reported by arm

\begin{tabular}{|c|c|c|}
\hline Event & Arm A, $100 \mathrm{mg} / \mathrm{m}^{2}(\boldsymbol{n}=79)$ & Arm B, $125 \mathrm{mg} / \mathrm{m}^{2}(\boldsymbol{n}=79)$ \\
\hline Median EFS, mos ( $90 \% \mathrm{Cl})$ & $\begin{array}{l}8.2(5.9-8.9) \\
6.2(5.8-8.4)^{\#}\end{array}$ & $\begin{array}{l}8.3(6.2-9.7) \\
6.4(5.8-7.7)^{\#}\end{array}$ \\
\hline Median EFS pts $75+$, mos $(90 \% \mathrm{Cl})$ & $\begin{array}{l}8.3(5.7-8.9) \\
5.9(5.1-8.3)^{\#}\end{array}$ & $\begin{array}{l}8.2(3.5-10.9) \\
6.9(5.5-8.3)^{\#}\end{array}$ \\
\hline Median PFS, mos (95\% Cl) & $8.3(5.9-10.5)$ & $8.8(7.4-10.3)$ \\
\hline Median OS, mos (95\% Cl) & $22.4(17.0-35.6)$ & $20.7(16.8-28.6)$ \\
\hline Best overall response*, $n(\%)$ & $n=60$ & $n=65$ \\
\hline$C R$ & $4(7)$ & $1(2)$ \\
\hline$P R$ & $20(33)$ & $26(40)$ \\
\hline SD & $24(40)$ & $18(28)$ \\
\hline PD & $9(15)$ & $14(21)$ \\
\hline NE & $3(5)$ & $6(9)$ \\
\hline
\end{tabular}

$C$ confidence interval, $C R$ complete response, EFS event-free survival, mos months, $N E$ not evaluable, $O S$ overall survival, $P F S$ progression-free survival, $P D$ progressive disease, $P R$ partial response, $S D$ stable disease

"Based on central review

*Patients with measurable disease

the development of Clostridium difficile infection, as well as the use of PPIs [19] and chemotherapy [20]. This may suggest that the concomitant use of PPIs with chemotherapy be made selectively and cautiously in older patients.

EFFECT evaluated weekly nab-paclitaxel specifically in patients aged $\geq 65$ years, in order to address this population's under-representation in previous clinical trials. However, a representative subgroup of patients aged $\geq$ 75 years $(n=66)$ allowed the evaluation of this agent in a strictly defined "older" population. Advanced age did not affect treatment feasibility and efficacy but was associated with a higher incidence of both neurotoxicity and fatigue with the $125 \mathrm{mg} / \mathrm{m}^{2}$ dose. Notably, two of the three reported deaths occurred in this age subgroup, suggesting a need for closer monitoring of AEs in this potentially less resilient population. The limitations of the unplanned subgroup analysis of patients aged 75 and over are acknowledged, highlighting the need to conduct prospective trials with adequate power to analyse this particular group of patients. Since the conception and completion of EFFECT, data has been published from a small phase II cohort study $(N=40)$ in patients aged 65 and older receiving $100 \mathrm{mg}$ of nab-paclitaxel on days 1 ,

Table 5 Adverse events reported in $\geq 20 \%$ of patients if grade 2 or if grades 3-4 occurring at any frequency

\begin{tabular}{|c|c|c|c|c|c|c|c|c|}
\hline \multirow[t]{2}{*}{ Adverse event, $\boldsymbol{n}(\%)$} & \multicolumn{4}{|c|}{ Arm A, $100 \mathrm{mg} / \mathrm{m}^{2}(\boldsymbol{n}=79)$} & \multicolumn{4}{|c|}{ Arm B, $125 \mathrm{mg} / \mathrm{m}^{2}(\boldsymbol{n}=79)$} \\
\hline & All & Grade 2 & Grade 3 & Grade 4 & All & Grade 2 & Grade 3 & Grade 4 \\
\hline Anaemia & $67(85)$ & $26(33)$ & $2(2.5)$ & - & $66(83.5)$ & $29(37)$ & - & - \\
\hline Leucopaenia & $47(59)$ & $20(25)$ & $7(9)$ & - & $58(73)$ & $23(29)$ & $15(19)$ & $1(1)$ \\
\hline Neutropaenia & $46(58)$ & $18(23)$ & $14(18)$ & $1(1)$ & $55(67)$ & $13(16)$ & $25(32)$ & $3(4)$ \\
\hline Fatigue & $60(76)$ & $25(32)$ & $9(11)$ & - & $60(76)$ & $36(46)$ & $4(5)$ & - \\
\hline Peripheral neuropathy & $43(54)$ & $12(15)$ & $3(4)$ & - & $51(64.5)$ & $22(28)$ & $8(10)$ & - \\
\hline Nausea/vomiting & $37(47)$ & $8(10)$ & $1(1)$ & - & $30(38)$ & $12(15)$ & $2(2.5)$ & - \\
\hline Alopecia & $35(44)$ & $24(30)$ & / & / & $32(40.5)$ & $21(27)$ & / & / \\
\hline Myalgia/arthralgia & $33(42)$ & $11(14)$ & $1(1)$ & - & $33(42)$ & $9(11)$ & - & - \\
\hline Dyspnoea & $14(18)$ & $4(5)$ & - & - & $15(19)$ & $1(1)$ & $1(1)$ & - \\
\hline Fever & $14(18)$ & $2(2.5)$ & - & - & $14(18)$ & - & $1(1)$ & - \\
\hline Hepatotoxicity & $14(18)$ & $5(6)$ & $2(2.5)$ & - & $16(20)$ & $1(1)$ & $1(1)$ & - \\
\hline Infection & $16(20)$ & $8(10)$ & $2(2.5)$ & $1(1)$ & $8(10)^{\circ}$ & $3(4)$ & - & - \\
\hline Diarrhoea & $11(14)$ & $3(4)$ & $4(5)$ & - & $15(19)^{\circ}$ & $5(6)$ & - & - \\
\hline Renal toxicity & $2(2.5)^{\circ}$ & - & $1(1)$ & - & $4(6)$ & $1(1)$ & - & - \\
\hline Febrile neutropenia & $1(1)$ & / & $1(1)$ & - & $2(2.5)$ & / & $2(2.5)$ & - \\
\hline
\end{tabular}

CTCAE Common Terminology Criteria for Adverse Events, / corresponding grade does not exist for this adverse event ${ }^{\circ}$ Grade $5(n=1)$ 
8 , and 15 on a 28 -day schedule [21]. Fifty-eight per cent of those patients had treatment-related toxicities at grade 3 or above, with $30 \%$ hospitalised as a consequence. This study was conducted in patients who exhibited a higher incidence of markers of vulnerability at baseline geriatric assessment than in the EFFECT population. This disparity might in part explain the higher incidence of toxicity observed in the former study when compared with the 100 $\mathrm{mg} / \mathrm{m}^{2}$ arm of EFFECT. This further underlines the importance of specifically studying optimal scheduling and dosing in older, vulnerable patient populations.

Reported outcomes in EFFECT were consistent with the first-line single-agent chemotherapy data in older breast cancer patients [22-24]. One of the limitations of this study is that it did not compare the performance of weekly nab-paclitaxel with conventional taxanes, such as solvent-based paclitaxel, which may be seen as the ideal comparator. Two studies have prospectively evaluated paclitaxel $80 \mathrm{mg} / \mathrm{m}^{2}$ weekly on days 1,8 , and 15 on a 28 -day cycle as the first-line therapy in small groups of older breast cancer patients $[19,20]$ and found it to be active. However, there were also some significant issues of safety, with one study reporting premature treatment discontinuation in $32 \%$ of patients due to fatigue [23] and the other observing toxicity-related treatment interruptions in $15 \%$ of patients (5 out of 7 events were due to cardiac toxicity, including two deaths), and grade $2 / 3$ sensory neurotoxicity in $33 \%$ of patients [24].

To our knowledge, this is the first prospective trial evaluating nab-paclitaxel in a numerically robust older population that specifically aims to identify the optimal dose for a population known to be at potentially higher risk of treatment-related toxicity. The inclusion of geriatric assessment and the identification of an elderlyrelated endpoint which included functional decline represent additional strengths of the study. EFS as an endpoint is in line with recommendations generated by the European Organisation for Research and Treatment of Cancer (EORTC) [25], which has advocated for alternative endpoints, such as QoL, toxicity, and functional independence to be considered as a way of improving the clinical design. The findings of EFFECT improve the evidence base for treating older adults with cancer, which is an area of unmet need identified by the American Society of Clinical Oncology [26].

\section{Conclusions}

Weekly taxanes are a suitable treatment option for older patients with MBC. Whilst solvent-based paclitaxel and solvent-based docetaxel are established options, the EFFECT trial has evaluated a role of weekly nab-paclitaxel in this selected population, identifying $100 \mathrm{mg} / \mathrm{m}^{2}$ on days 1,8 , and 15 on a 28 -day cycle as an effective and well-tolerated dose.

\section{Supplementary information}

Supplementary information accompanies this paper at https://doi.org/10. 1186/s13058-020-01319-1.

Additional File 1: Supplementary Table 1 (S1). Distribution of AEs by arm in patients aged $\geq 75$ years. Abbreviations: CTCAE, Common Terminology Criteria for Adverse Events; /, grade does not exist for this adverse event; ${ }^{\circ}$ grade $5 n=1$.

Additional File 2: Supplementary Table 2 (S2). Distribution of CTCAE G2-3 fatigue and neurotoxicity by age and arm of treatment. Reported as $\mathrm{N}(\%)$ unless otherwise indicated. Abbreviations: CTCAE, Common Terminology Criteria for Adverse Events.

\section{Abbreviations}

ABC: Advanced breast cancer; ADL: Activity of daily living; AEs: Adverse events; CBR: Clinical benefit rate; CIRS-G: Cumulative IIIness Rating ScaleGeriatric; CR: Complete response; EFS: Event-free survival; FD: Functional decline; G: Grade; HR: Hormone receptor; IADL: Instrumental activity of daily living; ORR: Objective response rate; OS: Overall survival; PD: Progressive disease; PFS: Progression-free survival; PR: Partial response; Pts: Patients; SD: Stable disease

\section{Acknowledgements}

The authors would like to thank our patients and their families for their invaluable contributions to the EFFECT study. We thank Daniela Baldari for her role in coordinating study data management.

\section{Authors' contributions}

$L B i, G M, F P$, and LBo were involved in the conception and design of the study. LBi, SC, RB, RPe, AMM, REC, SS, EM, AB, ER, RPa, SL, MC, SD, SDP, LO, $M P, V P, D B, F P, G S, E Z$, and GM were involved in the acquisition of the data (recruited and managed patients, provided facilities). LBO, AMC, AMi, and LBi were involved in the collection, assembly, analysis, and interpretation of the data (e.g. statistical analysis, biostatistics, computational analysis). All authors were involved in the writing, review, and revision of this manuscript. All authors read and approved the final manuscript.

\section{Funding}

The trial was an academic study sponsored by the not-for-profit foundation "Sandro Pitigliani per la lotta contro i Tumori ONLUS" and was funded by Celgene through an investigator-initiated research grant. Celgene had no influence on the design or conduct of the trial and was not involved in the reporting of the data and its interpretation.

\section{Availability of data and materials}

On reasonable request, the data generated and analysed during the current study are available from the corresponding author in accordance with institutional policies.

\section{Ethics approval and consent to participate}

The study was conducted in accordance with the principles of the Declaration of Helsinki and Good Clinical Practice Guidelines of the Internal Conference on Harmonisation. The protocol and any accompanying material provided to patients were prospectively approved by the local independent ethics committee at each of the 15 participating sites.

\section{Consent for publication}

Not applicable.

\section{Competing interests}

DB has received honoraria from Pfizer, Daiichi Sankyo, and MDM and research funding from Daiichi Sankyo. RB has undertaken a consulting or advisory role with Otsuka and Boeringher. LBi has received honoraria from Lilly, Novartis, and Pfizer; has undertaken a consulting or advisory role with AstraZeneca, Celgene, Daiichi-Sankyo, Eisai, Genomic Health, Ipsen, Lilly, Novartis, Pfizer, Pierre Fabre, and Roche; has received research funding (institutional) from Celgene, Genomic Health, and Novartis; and has received travel, accommodation, or expenses from Celgene, Pfizer, Ipsen, and Roche. $A B$ has undertaken a consulting or advisory role with Eisai, Roche, and Eli Lilly and has received research funding from Roche and travel, 
accommodations, or expenses from Eli Lilly and Pharmamar. SC has undertaken a consulting or advisory role with Lilly. MC has received honoraria from Novartis and has undertaken a consulting or advisory role with Pierre Fabre, Pfizer, OBI Pharma, Puma Biotechnology, Celldex, and AstraZeneca. SDP has received honoraria from Roche, Celgene, GSK, Novartis, Ipsen, and AstraZeneca; has undertaken a consulting or advisory role with Roche, Celgene, GSK, Novartis, Ipsen, Lilly, Pfizer, and AstraZeneca; has served on speaker's bureau with Roche, Novartis, Lilly, Pfizer, AstraZeneca, Celgene, Eisai, and Istituto Gentili; has received research funding from Eisai, Novartis, Roche; and AstraZeneca, and travel, accommodation; and expenses from Roche, GSK, Novartis, Liilly, Pfizer, Eisai, and AstraZeneca. SD has received travel, accommodation, or expenses from Roche, Novartis, and Takeda. AMM has undertaken a consulting or advisory role with Novartis, Merck Sharp \& Dohme, and Pierre Fabre. MP has received honoraria from Celgene, Novartis, Pfizer, and Istituto Gentili; has undertaken a consulting or advisory role with Novartis and Sandoz; and received travel, accommodation, or expenses from Celgene and Istituto Gentili. FP has received honoraria from Amgen, Eli Lilly, Ipsen, Merck Sharp \& Dohme, Roche, and Takeda; has undertaken a consulting or advisory role with Eisai, Eli Lilly, Novartis, Pfizer, Pierre Fabre, and Roche; has received research funding from AstraZeneca, Eisai, and Roche; and received travel, accommodation, or expenses from Celgene and Roche. ER has received travel, accommodation, or expenses from Pfizer. GS has received honoraria from Novartis, has undertaken a consulting or advisory role with Roche, and has received travel, accommodation, or expenses from Eisai, Novartis, Pfizer, Pierre Fabre, and Roche. SS has received honoraria from Pfizer and Novartis; has undertaken a consulting or advisory role with Novartis and has received research funding (institution) from Roche, Novartis, and Abbott, and travel, accommodations or expenses from Pfizer, Istituto Gentili, and Tesaro. All remaining authors declare that they have no competing interests.

\section{Author details}

"Sandro Pitigliani" Department of Medical Oncology, Hospital of Prato, ASL Toscana Centro, Prato, Italy. ${ }^{2}$ Department of Medical Oncology, Perrino Hospital, ASL Brindisi, Brindisi, Italy. ${ }^{3}$ Department of Medical Oncology, Ospedali Riuniti di Ancona, Università Politecnica delle Marche, Ancona, Italy. ${ }^{4}$ Breast Oncology Unit, Hospital Civili di Brescia, Brescia, Italy. ${ }^{5}$ Department of Oncology, Azienda Ospedaliero Universitaria Integrata di Udine, Udine, Italy. ${ }^{6}$ Cancer Centre, Azienda Socio Sanitaria Territoriale Papa Giovanni XXIII, Bergamo, Italy. ${ }^{7}$ Unit of Medical Oncology and Cancer Prevention, IRCCS CRO di Aviano, National Cancer Institute, Aviano, Italy. ${ }^{8}$ Department of Medical Oncology, Hospital Civile SS Trinità di Sora, Frosinone, Italy. ${ }^{9}$ Department of Medical Oncology, Veneto Institute of Oncology IOV Padova, Padua, Italy. ${ }^{10}$ Department of Medical Oncology, IRCCS ICS Maugeri, Pavia, Italy. ${ }^{11}$ Department of Medical Oncology, Vito Fazzi Hospital, Lecce, Italy. ${ }^{12}$ Division of Medical Senology, IEO, European Institute of Oncology IRCCS, Milan, Italy. ${ }^{13}$ Department of Oncology, Versilia Hospital (Camaiore-Lu), Viareggio, Italy. ${ }^{14}$ Department of Endocrinology and Molecular and Clinical Oncology, AOU Federico II, Naples, Italy. ${ }^{15}$ Department of Medical Oncology, Azienda Ospedaliera Universitaria Integrata, Verona, Italy. ${ }^{16}$ Flinders Centre for Innovation in Cancer, Flinders Medical Centre, Bedford Park, South Australia, Australia. ${ }^{17}$ Geriatric Medicine Unit, AUSL Toscana Centro, Prato, Italy.

${ }^{18}$ Clinical Trials Centre, AOU University Hospital Careggi, Florence, Italy.

\section{Received: 20 February 2020 Accepted: 22 July 2020}

Published online: 05 August 2020

\section{References}

1. van Abbema DL, van den Akker M, Janssen-Heijnen ML, van den Berkmortel F, Hoeben A, de Vos-Geelen J, Buntinx F, et al. Patient- and tumor-related predictors of chemotherapy intolerance in older patients with cancer: a systematic review. J Ger Oncol. 2019;10(1):31-41.

2. Biganzoli L, Wildiers H, Oakman C, Marotti L, Loibl S, Kunkler I, et al. Management of elderly patients with breast cancer: updated recommendations of the International Society of Geriatric Oncology (SIOG) and European Society of Breast Cancer Specialists (EUSOMA). Lancet Oncol. 2012;13(4):e148-60.

3. Biganzoli L, Aapro M, Loibl S, Wildiers H, Brain E. Taxanes in the treatment of breast cancer: have we better defined their role in older patients? A position paper from a SIOG Task Force. Cancer Treat Rev. 2016:43:19-26.
4. Biganzoli L, Licitra S, Moretti E, Pestrin M, Zafarana E, Di Leo A. Taxanes in the elderly: can we gain as much and be less toxic? Crit Rev Oncol Hematol. 2009;70(3):262-71.

5. Lichtman SM, Hurria A, Cirrincione CT, Seidman AD, Winer E, Hudis C, et al. Paclitaxel efficacy and toxicity in older women with metastatic breast cancer: combined analysis of CALGB 9342 and 9840. Ann Oncol. 2012;23(3): 632-8.

6. Luciani A, Jacobsen PB, Extermann M, Foa P, Marussi D, Overcash JA, Balducci L. Fatigue and functional dependence in older cancer patients. Am J Clin Oncol. 2008;31(5):424-30. https://doi.org/10.1097/COC. Ob013e31816d915f.

7. Kenis C, Decoster L, Bastin J, et al. Functional decline in older patients with cancer receiving chemotherapy: a multicenter prospective study. J Geriatr Oncol. 2017:8(3):196-205. https://doi.org/10.1016/j.jgo.2017.02.010.

8. Gradishar WJ, Tjulandin S, Davidson N, Shaw H, Desai N, Bhar P, et al. Phase III trial of nanoparticle albumin-bound paclitaxel compared with polyethylated castor oil-based paclitaxel in women with breast cancer. J Clin Oncol. 2005;23(31):7794-803.

9. Gradishar WJ, Krasnojon D, Cheporov S, Makhson AN, Manikhas GM Clawson A, et al. Significantly longer progression-free survival with nabpaclitaxel compared with docetaxel as first-line therapy for metastatic breast cancer. J Clin Oncol. 2009;27(22):3611-9.

10. Liu Y, Ye G, Yan D, Zhang L, Fan F, Feng J. Role of nab-paclitaxel in metastatic breast cancer: a meta-analysis of randomized clinical trials. Oncotarget. 2017:8(42):72950-8.

11. Aapro M, Tjulandin S, Bhar P, Gradishar W. Weekly nab-paclitaxel is safe and effective in $\geq 65$ years old patients with metastatic breast cancer: a post-hoc analysis. Breast. 2011;20(5):468-74.

12. Miller MD, Paradis CF, Houck PR, Mazumdar S, Stack JA, Rifai AH, et al. Rating chronic medical illness burden in geropsychiatric practice and research: application of the Cumulative IIIness Rating Scale. Psychiatry Res. 1992;41(3):237-48.

13. Katz S, Downs TD, Cash HR, Grotz RC. Progress in development of the index of ADL. Gerontologist. 1970;10(1):20-30.

14. Lawton MP, Brody EM. Assessment of older people: self-maintaining and instrumental activities of daily living. Gerontologist. 1969;9(3):179-86.

15. Brookmeyer R, Crowley J. A confidence interval for the median survival time. Biometrics. 1982;38(1):29.

16. Blum JL, Savin MA, Edelman G, Pippen JE, Robert NJ, Geister BV, et al. Phase II study of weekly albumin-bound paclitaxel for patients with metastatic breast cancer heavily pretreated with taxanes. Clin Breast Cancer. 2007;7(11): 850-6.

17. Bossi P, Antonuzzo A, Cherny NI, Rosengarten O, Pernot S, Trippa F, et al. Diarrhoea in adult cancer patients: ESMO Clinical Practice Guidelines. Ann Oncol. 2018;29(Supp 4):iv126-42.

18. Network NCC. NCCN Clinical Practice Guidelines in Oncology. Older adult oncology. Version 1. 2018. 2018 [Available from: https://www.nccn.org/ professionals/physician_gls/pdf/senior.pdf.

19. Trifan A, Stanciu C, Girleanu I, Stoica OC, Singeap AM, Maxim R, et al. Proton pump inhibitors therapy and risk of Clostridium difficile infection: systematic review and meta-analysis. World J Gastroenterol. 2017;23(35):6500-15.

20. Neemann K, Freifeld A. Clostridium difficile-associated diarrhea in the oncology patient. J Oncol Pract. 2017;13(1):25-30.

21. Hurria A, Soto-Perez-de-Celis E, Blanchard S, Burhenn P, Yeon CH, Yuan Y, et al. A phase II trial of older adults with metastatic breast cancer receiving nab-paclitaxel: melding the fields of geriatrics and oncology. Clin Breast Cancer. 2019;19(2):89-96. https://doi.org/10.1016/j.clbc.2018.10.002.

22. Smorenburg $\mathrm{CH}$, de Groot $\mathrm{SM}$, van Leeuwen-Stok AE, Hamaker ME, Wymenga AN, de Graaf H, et al. A randomized phase III study comparing pegylated liposomal doxorubicin with capecitabine as first-line chemotherapy in elderly patients with metastatic breast cancer: results of the OMEGA study of the Dutch Breast Cancer Research Group BOOG. Ann Oncol. 2014;25(3):599-605.

23. ten Tije AJ, Smorenburg CH, Seynaeve C, Sparreboom A, Schothorst KLC, Kerkhofs LGM, et al. Weekly paclitaxel as first-line chemotherapy for elderly patients with metastatic breast cancer. A multicentre phase II trial. Eur J Cancer. 2004;40(3):352-7.

24. Del Mastro L, Perrone F, Repetto L, Manzione L, Zagonel V, Fratino L, et al. Weekly paclitaxel as first-line chemotherapy in elderly advanced breast cancer patients: a phase II study of the Gruppo Italiano di Oncologia Geriatrica (GlOGer). Ann Oncol. 2005;16:253-8. 
25. Pallis AG, Ring A, Fortpied C, Penninckx B, Van Nes MC, Wedding U, et al. EORTC workshop on clinical trial methodology in older individuals with a diagnosis of solid tumors. Ann Oncol. 2011;22(8):1922-6. https://doi.org/10. 1093/annonc/mda687.

26. Hurria A, Levit LA, Dale W, Mohile SG, Muss HB, Fehrenbacher L, et al. Improving the evidence base for treating older adults with cancer:

American Society of Clinical Oncology Statement. J Clin Oncol. 2015;33(32): 3826-33. https://doi.org/10.1200/JCO.2015.63.0319.

\section{Publisher's Note}

Springer Nature remains neutral with regard to jurisdictional claims in published maps and institutional affiliations.

Ready to submit your research? Choose BMC and benefit from:

- fast, convenient online submission

- thorough peer review by experienced researchers in your field

- rapid publication on acceptance

- support for research data, including large and complex data types

- gold Open Access which fosters wider collaboration and increased citations

- maximum visibility for your research: over $100 \mathrm{M}$ website views per year

At $\mathrm{BMC}$, research is always in progress.

Learn more biomedcentral.com/submissions 